\title{
Prevalência e multiplicidade do papilomavírus humano (HPV) na cérvice uterina de mulheres infectadas pelo vírus da imunodeficiência humana (HIV)
}

\author{
Prevalence and multiplicity of buman papillomavirus in cervix uterine \\ of women infected with buman immunodeficiency virus (HIV)
}

Palavras-chave

Papilomavírus humano Vírus da imunodeficiência humana Reação em cadeia de polimerase

Cérvice uterina Infecção múltipla

Dissertação apresentada à Área de Concentração em Ciências da Reprodução, Patologia Mamária e Ginecológica e Perinatologia da Faculdade de Medicina da Universidade Federal de Minas em 29 de maio de 2007.

OBJETIVO: determinar a prevalência e a multiplicidade do HPV na cérvice uterina de mulheres infectadas pelo HIV. MÉTODOS: foram avaliadas 288 pacientes atendidas no Centro de Treinamento e Referência de Doenças Infecciosas e Parasitárias (CTR-DIP) Orestes Diniz da Prefeitura Municipal de Belo Horizonte, em convênio com a Universidade Federal de Minas Gerais (UFMG), e no sistema público de saúde de Betim, Barbacena, Conselheiro Lafaiete e Divinópolis. De agosto de 2003 a agosto de 2006, realizaram-se: anamnese, exame ginecológico com coleta de material para detecção do HPV pela PCR, colpocitologia oncótica, colposcopia e biópsia, esta quando indicada. Os dados foram analisados no Epi-Info, versão 3.3.2. Para análise das variáveis categórica, foi empregado o teste do $\chi^{2}$. Foram considerados 5\% como limiar de significância estatística. RESULTADOS: a prevalência do HPV foi alta (78,8\%). Os genótipos mais prevalentes foram HPV-6 $(63,9 \%)$ e HPV-16 (48,5\%). A taxa de pacientes com HPV detectado, mas não genotipado, variou de 0 a 11 1 1\%. A presença do HPV de alto risco foi observada em $160(70,5 \%)$ casos, do HPV de baixo risco em $162(71,4 \%)$ e do HPV de alto e baixo risco concomitante em 125 (55, 1\%). A infecção por múltiplos genótipos do HPV manifestou-se em $64,8 \%$ das pacientes, com predomínio de dois $(23,8 \%)$ e três $(18,9 \%)$ tipos. Não houve associação significante entre a prevalência do HPV e uso de preservativo, número de parceiros sexuais, contagem de linfócitos T CD4 e quantificação da carga viral do HIV. CONCLUSÕES: a prevalência de HPV em mulheres infectadas pelo HIV é alta. A infecção por múltiplos genótipos foi o padrão predominante de infecção pelo HPV.

AUTOR:

Mariana Maia Freire de Oliveira

ORIENTADOR:

Prof. Dr. Gustavo Antonio de Sousa

CO-Orientadora:

Profa. Dra. Maria Salete Costa Gurgel

Resumo de tese

\section{Eficácia da fisioterapia realizada durante a radioterapia na prevenção de complicações loco-regionais em mulheres em tratamento por câncer de mama: ensaio clínico controlado}

\author{
Efficacy of physiotherapy performed during radiotherapy in the prevention \\ of locoregional complications in women under treatment for breast cancer:
}

a controlled clinical trial

Palavras-chave

Câncer de mama Radioterapia Morbidade Fisioterapia
Dissertação de Mestrado apresentada ao Departamento de Tocoginecologia da Faculdade de Ciências Médicas da Universidade Estadula de Campinas (Unicamp), em 26 de janeiro de 2007

INTRODUÇÃO: a fisioterapia no pós-operatório de câncer de mama visa prevenir complicações e promover independência funcional. Porém, não há dados na literatura sobre a influência da fisioterapia realizada durante a radioterapia, bem como qual a melhor abordagem. OBJETIVO: verificar a influência da fisioterapia realizada durante a radioterapia nas complicações físicas loco-regionais: limitação da amplitude de movimento e da capacidade funcional, aumento da circunferência do braço e aderência cicatricial. MÉTODOS: ensaio clínico controlado randomizado, realizado no Serviço de Fisioterapia do Centro de Atenção Integral à Saúde da Mulher da Universidade Estadual de Campinas (CAISM/Unicamp), com 66 mulheres em tratamento radioterápico após cirurgia para câncer de mama e fisioterapia pós-operatória. As mulheres foram alocadas no Grupo 1 (G1, 32), que realizou fisioterapia, e no Grupo 2 (G2, 34), controle, sendo avaliadas no início e no final da RT e seis meses após término. A amplitude de movimento do ombro foi avaliada pela goniometria, a circunferência do braço, pela cirtometria e a aderência cicatricial, pela palpação e fricção cicatricial. A capacidade funcional foi graduada pelo escore de dificuldade para movimentar o ombro. Para cálculos estatísticos, foi utilizado MANOVA com estatíisitca de Wilks ou Friedman e os testes de associação $\chi^{2}$ ou exato de Fisher,

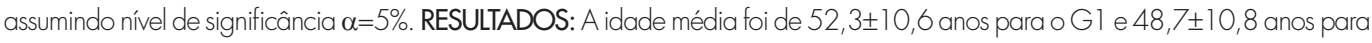
- G2. Os valores médios de amplitude de movimento do ombro para abdução e flexão observados nas três avaliações revelaram melhores resultados para G1 em relação ao $G 2$ (p=0,0244 e 0,0044, respectivamente). Na avaliação final, a freqüência de aderência cicatricial no Gl foi duas vezes menor que a observada no G2 (24 e 48\%, p=0,0477). CONCLUSÕES: a fisioterapia realizada durante a radioterapia para tratamento de câncer de mama previne a limitação na amplitude de movimento do ombro, minimiza a incidência de aderência cicatricial e parece favorecer a melhora da capacidade funcional. No período estudado, não foi encontrada associação entre a realização da fisioterapia e alteração na circunferência do braço. 